\title{
Dietary fibre supplementation with psyllium or gum arabic reduced incontinent stools and improved stool consistency in community living adults
}

Bliss DZ,Jung H-J, Savik K, et al. Supplementation with dietary fiber improves fecal incontinence. Nurs Res 2001 Jul-Aug;50:203-13.

\section{QUESTION: Does dietary fibre supplementation with psyllium or gum arabic improve faecal incontinence in community living adults with incontinence of loose or liquid stools?}

\section{Design}

Randomised \{allocation concealed\}*, blinded \{participants, clinicians, and data analysts $\}$, placebo controlled trial with 8 day post-intervention comparison.

Setting

Colorectal surgical practice in Minneapolis, Minnesota, USA.

\section{Participants}

42 adults (mean age 61 y) with at least weekly faecal incontinence of loose or liquid stools. Exclusion criteria were rectal prolapse, colon cancer, rectal fistula, ulcerative colitis, or removal of some portion of the gastrointestinal tract. Follow up was 93\%.

\section{Intervention}

Participants were allocated to receive 31 days of dietary fibre supplementation with psyllium, $7.1 \mathrm{~g} /$ day $(\mathrm{n}=13)$, or gum arabic, $25 \mathrm{~g}$ /day $(\mathrm{n}=13)$; or placebo given as pectin, $0.25 \mathrm{~g} /$ day $(\mathrm{n}=13)$. Supplementation was mixed into fruit juice and divided into 2 servings for consumption during the morning and evening meals. Participants were instructed to maintain their usual diet, and those who were taking antidiarrhoeal medication were advised not to alter the type and amount during the study. No participant had biofeedback training for pelvic muscle exercises.

\section{Main outcome measures}

Daily self reported stool characteristics including rate of incontinent stools, stool consistency, stool frequency, and stool weight.

Sources of funding: National Institute of Nursing Research; National Institute of Health; the American Federation for Aging Research; Sigma Theta Tau Zeta.

For correspondence: Dr D Z Bliss, University of Minnesota School of Nursing, Minneapolis, $M N, U S A$.

bliss@tc.umn.edu

A modified version of this abstract appears in

Evidence-Based

Medicine.

\section{Main results}

The psyllium and gum arabic groups had lower proportions of incontinent stools than the placebo group ( $17 \%$ and $18 \% v 50 \%$, respectively, $\mathrm{p}=0.002$ ), as well as lower proportions of loose and unformed or liquid stools for stool frequency, wet weight of stool, or weight of total stool solids.

\section{Conclusion}

In community living adults, dietary fibre supplementation with psyllium or gum arabic reduced the proportion of incontinent stools and improved stool consistency.

*Information provided by the author $(\mathrm{p}=0.002)$. No difference existed between the 3 groups

\section{COMMENTARY}

Faecal incontinence affects $>1 \%$ of adults in the community and is associated with increased age, poor general health, limited physical activity, and diminished mental capacity. The prevalence, burden of illness, and social costs of faecal incontinence among community living adults is largely overlooked in comparison to the well documented problem of faecal incontinence in long term care institutions for the elderly. ${ }^{2}$ Multiple reasons exist for dysfunction of the anal muscle tissue and damage to the anal sphincter.

Bliss $e t$ al report the first randomised controlled trial of this topic, focusing on community living adults. The dietary fibre treatments were inexpensive, palatable, and easy to use over the counter products. Because of the complexity of the condition, information on individual causes and contributory comorbid factors would have been helpful in determining the generalisability of the study results. The small sample size further highlights the need for larger effectiveness trials before a change in clinical practice can be recommended. The authors also point out the need for longer term evaluation of the treatment's clinical usefulness and whether symptom improvements are sustained with long term management.

The study is relevant to nursing staff in acute care settings and the community, particularly those working with aged and aging populations. Simple measures are important among older adults where faecal incontinence is often treatable and preventable. The normalisation of faecal consistency and other conservative treatments such as relief of faecal impaction, increased mobility, and regular toileting can also help to relieve this condition.

This is an important study that reinforces the need to more fully understand this chronic condition and to further explore simple but effective long term treatments. Susan Campbell, RN, MSc Research Fellow, University of Aberdeen Aberdeen, $U K$

1 Nelson R, Norton N, Cautley E, et al. Community-based prevalence of anal incontinence. JAMA 1995;274:559-61.

2 Johanson JF, Lafferty J. Epidemiology of fecal incontinence: the silent affliction. Am J Gastroenterol 1996;91:33-6.

3 Barrett JA. Faecal incontinence and related problems in the older adult. London: Edward Arnold, 1993.

4 Perry S, Assassa RP, Williams K, et al. Author overestimated need in community population with faecal incontinence. BMJ 1998;317:415. 